\title{
Molecular and Antifilarial IgG4 Detection Using the miniPCR-Duplex Lateral Flow Dipstick and BmSxp-ELISA in Myanmar Immigrant Communities
}

\author{
Patimaporn Wongprompitak $^{1}$, Navapon Kusuwan ${ }^{2}$, Ladawan Khowawisetsut ${ }^{3} \mathbb{D}$, Achinya Phuakrod ${ }^{3}$, \\ Duangnate Pipatsatitpong ${ }^{2, *,+}$ and Sirichit Wongkamchai ${ }^{3, *,+} \mathbb{D}$ \\ 1 Department of Immunology, Faculty of Medicine Siriraj Hospital, Mahidol University, \\ Bangkok 10700, Thailand; patimaporn.won@mahidol.ac.th \\ 2 Graduate Program in Medical Technology, Faculty of Allied Health Sciences, Thammasat University, \\ Pathum Thani 12120, Thailand; navaponkusuwan@hotmail.com \\ 3 Department of Parasitology, Faculty of Medicine Siriraj Hospital, Mahidol University, \\ Bangkok 10700, Thailand; ladawan.kho@mahidol.ac.th (L.K.); lek.achinya@gmail.com (A.P.) \\ * Correspondence: duangnate_pipat@hotmail.com (D.P.); sirichit.won@mahidol.ac.th (S.W.) \\ + These authors contributed equally to this work.
}

\section{check for}

updates

Citation: Wongprompitak, P.;

Kusuwan, N.; Khowawisetsut, L.;

Phuakrod, A.; Pipatsatitpong, D.;

Wongkamchai, S. Molecular and

Antifilarial IgG4 Detection Using the

miniPCR-Duplex Lateral Flow

Dipstick and BmSxp-ELISA in

Myanmar Immigrant Communities.

Parasitologia 2022, 2, 27-36. https:/ / doi.org/10.3390/parasitologia2010003

Academic Editor: Christina Strube

Received: 7 January 2022

Accepted: 14 February 2022

Published: 17 February 2022

Publisher's Note: MDPI stays neutral with regard to jurisdictional claims in published maps and institutional affiliations.

Copyright: (C) 2022 by the authors. Licensee MDPI, Basel, Switzerland. This article is an open access article distributed under the terms and conditions of the Creative Commons Attribution (CC BY) license (https:// creativecommons.org/licenses/by/ $4.0 /)$.

\begin{abstract}
Lymphatic filariasis (LF) is an important tropical disease that affects over a billion people in more than 80 countries and approximately 40 million people are currently suffering from severe disfigurement and disability. A diagnostic tool is the principal impact factor to determine the infection status of lymphatic filariasis. The purpose of the present study was to investigate nucleic acid of Wuchereria bancrofti as well as antifilarial IgG4 in a Myanmar immigrant community living along the Moei River, a natural border between Mae Sot, Tak province Thailand and Myawaddy, Myanmar which is an endemic area of bancroftian filariasis. Blood was collected from 300 Myanmar immigrants in Mae Sot district, Tak Province. The nucleic acid of W. bancrofti was assessed in the study population using our recent published miniPCR-Duplex Lateral Flow dipstick (DLFD) platform as well as the standard PCR technique. The antifilarial IgG4 was detected in the study population using the developed ELISA which used BmSxp protein as antigen. The miniPCR-DLFD method delivered results comparable to the standard PCR technique and it enables convenient and rapid visual detection of the parasite nucleic acid. Furthermore, the ELISA using BmSxp antigen demonstrated a sensitivity, specificity, and positive and negative predictive values of $98.1 \%, 98.9 \%$, $96.3 \%$, and $99.4 \%$ respectively. The W. bancrofti nucleic acid and antifilarial IgG4 were detected in $1.6 \%(5 / 300)$, and $2 \%(6 / 300)$ of the study population, accordingly. The results of this study also revealed important epidemiological data about LF on the Thai-Myanmar border.
\end{abstract}

Keywords: Wuchereria bancrofti DNA; miniPCR; duplex lateral flow dipstick; DLFD; antifilarial IgG4 antibodies; Myanmar immigrant communities

\section{Introduction}

Lymphatic filariasis (LF) is an important tropical disease that is caused by three main species of filarial worms (Wuchereria bancrofti, Brugia malayi, and B. timori) that inhabit the lymph system [1]. The Global Program to Eliminate Lymphatic Filariasis (GPELF) was launched by the WHO in 2002. The program recommended that all countries and at-risk communities in endemic areas receive mass drug administration (MDA) to eliminate microfilariae and interrupt transmission by mosquitoes [2]. Before the GPELF, over a billion people in more than 80 countries were at risk of contracting LF, over 120 million people have already been affected by the disease, and approximately 40 million people are currently suffering from severe disfigurement and disability [3,4].

LF has historically been endemic only in some parts of Thailand, and both brugian and bancroftian filariasis were identified [5]. From 2002 to 2011, Thailand conducted MDA 
with high coverage rates. In September 2017, the WHO acknowledged that Thailand had eliminated lymphatic filariasis as a public health problem [5]. However, Thailand shares a very long border with Myanmar, which has several LF endemic provinces along that border, and $W$. bancrofti is the predominant causative organism. Many people from Myanmar migrate to Thailand, so there is a risk of $W$. bancroft $i$ transmission across the Thai-Myanmar border. Among Southeast Asian countries and specific to the effect of LF, Myanmar is considered to be a high-burden country [6].

The decision to discontinue MDA does not require the complete absence of filarial parasites, but rather a reduction of parasite numbers to such low quantities that transmission will cease [7]. A diagnostic tool is, therefore, needed to determine when the prevalence levels have decreased to a point where MDA campaigns can be discontinued without the threat of recrudescence [8]. To achieve the goal, highly sensitive and specific diagnostic tests are needed for close monitoring and evaluation of the LF control program.

The aims of the present study were to investigate the prevalence of antifilarial IgG4 as well as prevalence of $W$. bancroft $i$ DNA in a Myanmar immigrant community living along the Moei River, a natural border between Mae Sot, Tak province Thailand and Myawaddy, Myanmar which is endemic areas of bancroftian filariasis (Figure 1).

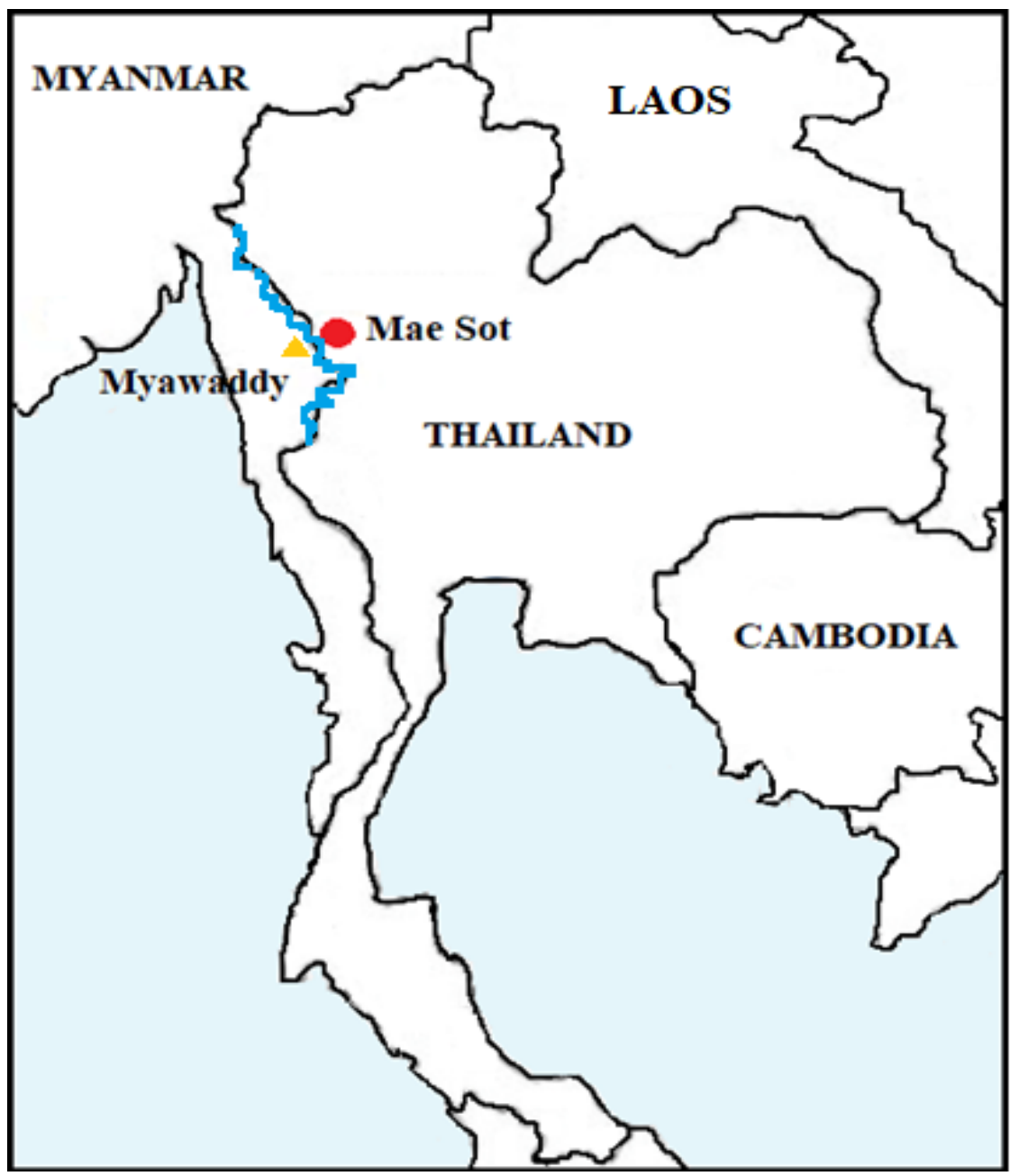

Figure 1. Map showing the locations of the study sites (red dot); The Moei River (blue line) serves as a natural border between Mae Sot and Myawaddy (yellow triangle), which is located in Myanmar's Kayin State.

In the present study, we developed BmSXP antigen-based ELISA for detection of antifilarial IgG4 and used to assess the prevalence of antifilarial IgG4 in Myanmar immigrant 
communities living in Mae Sot, Thailand. We also assess the prevalence of W. bancrofti DNA using our recent developed miniPCR-duplex lateral flow dipstick platform.

\section{Results}

Table 1 shows the age distribution of the study population, which consisted of 119 $(39.7 \%)$ males and $181(60.3 \%)$ females. The median age at the different study sites ranged from 11 years to 30 years. The mean age of the overall study population was $26.3 \pm 13$ years. Figure 2 shows the result of $W$. bancrofti DNA obtained from the miniPCR-DLFD and from conventional PCR followed by agarose gel electrophoresis. The detection results were similar between the two detection methods. Both assays detected W. bancrofti DNA from 5 out of 300 samples ( $1.6 \%$ of the study population).

Table 1. Summary of data of the study population including the age range, sex; antifilarial IgG4 antibodies and $W$. bancrofti DNA detected.

\begin{tabular}{ccccccc}
\hline \multirow{2}{*}{$\begin{array}{c}\text { Age Range } \\
\text { (Years) }\end{array}$} & Number & $\begin{array}{c}\text { Antifilarial } \\
\text { IgG4 }\end{array}$ & $\begin{array}{c}\text { W. bancrofti } \\
\text { DNA }\end{array}$ & Number & $\begin{array}{c}\text { Antifilarial } \\
\text { IgG4 }\end{array}$ & $\begin{array}{c}\text { W. bancrofti } \\
\text { DNA }\end{array}$ \\
\cline { 2 - 7 } & 3 & 0 & 0 & 9 & 0 & 0 \\
$0-10$ & 45 & 0 & 0 & 74 & 0 & 0 \\
$11-20$ & 37 & 2 & 2 & 41 & 2 & 2 \\
$21-30$ & 17 & 1 & 1 & 14 & 0 & 0 \\
$31-40$ & 12 & 1 & 0 & 10 & 0 & 0 \\
$41-50$ & 1 & 0 & 0 & 4 & 0 & 0 \\
$51-60$ & 119 & 4 & 3 & 181 & 2 & 2 \\
$>60$ & & 0 & & & \\
\hline
\end{tabular}

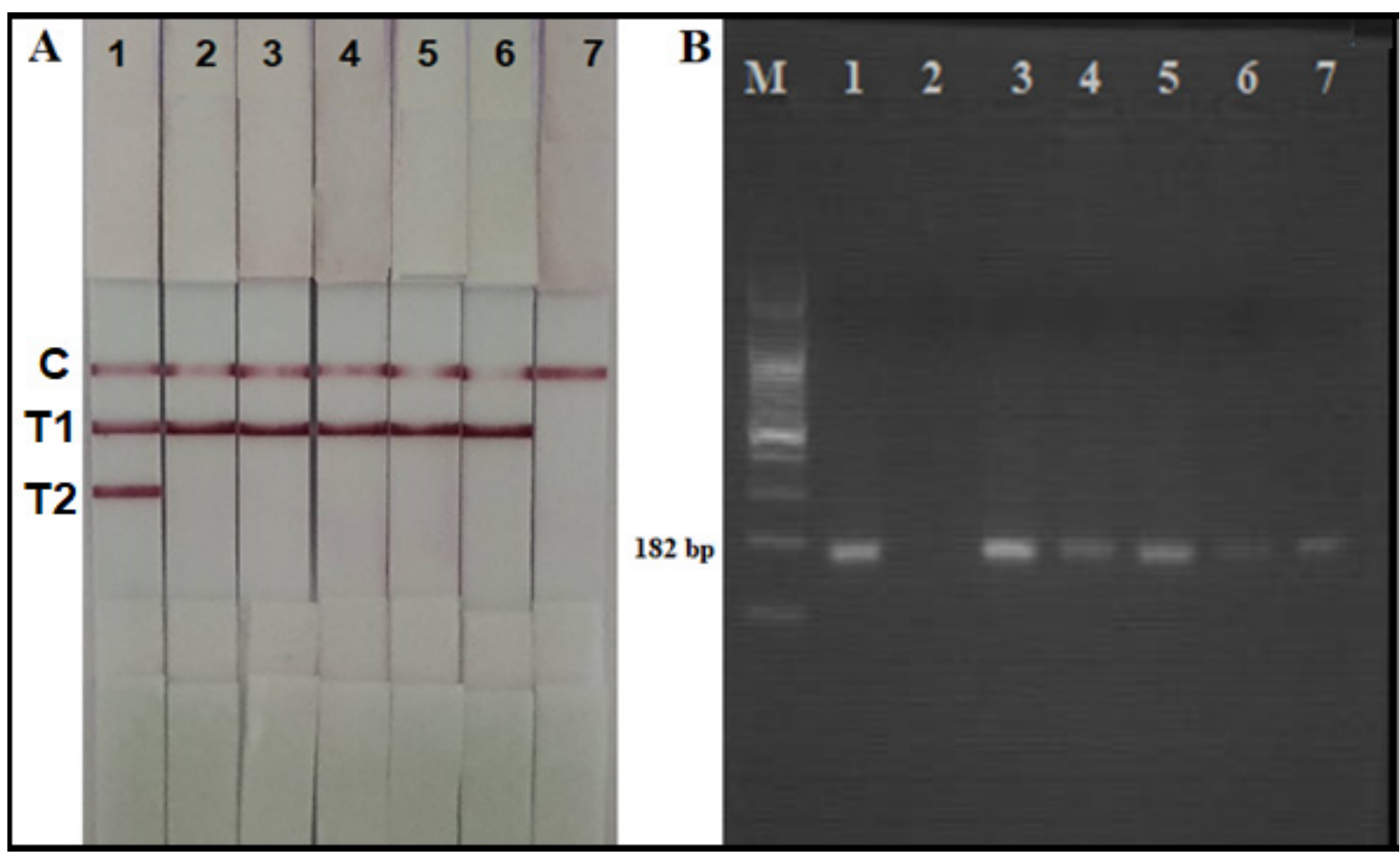

Figure 2. The result of $W$. bancrofti DNA obtained from the miniPCR-DLFD (A) and from conventional PCR followed by agarose gel electrophoresis (B).

ROC curve analysis was used to determine the cut-off OD value with the best sensitivity and specificity for detecting of antifilarial IgG4 by the ELISA test developed for 
use in this study (Figure 3). The cut-off OD values from mean $\pm \mathrm{SD}$ to mean $\pm 13.0 \mathrm{SD}$ ranged from 0.12 to 0.36 . The true positive rate (or sensitivity) was plotted relative to the false-positive rate (specificity) for different cut-off points, so each point on the ROC plot represents a sensitivity-specificity pair corresponding to a particular cut-off $O D$ value. The optimal cut-off value, which yielded the highest specificity and sensitivity, was 0.2 , with a sensitivity of $98.1 \%$ and a specificity of $98.9 \%$. Therefore, the OD of 0.2 was selected as the cut-off value for the ELISA test developed to detect antifilarial IgG4 in this study. Antifilarial IgG4 was detected in $2 \%(6 / 300)$ of the study population.

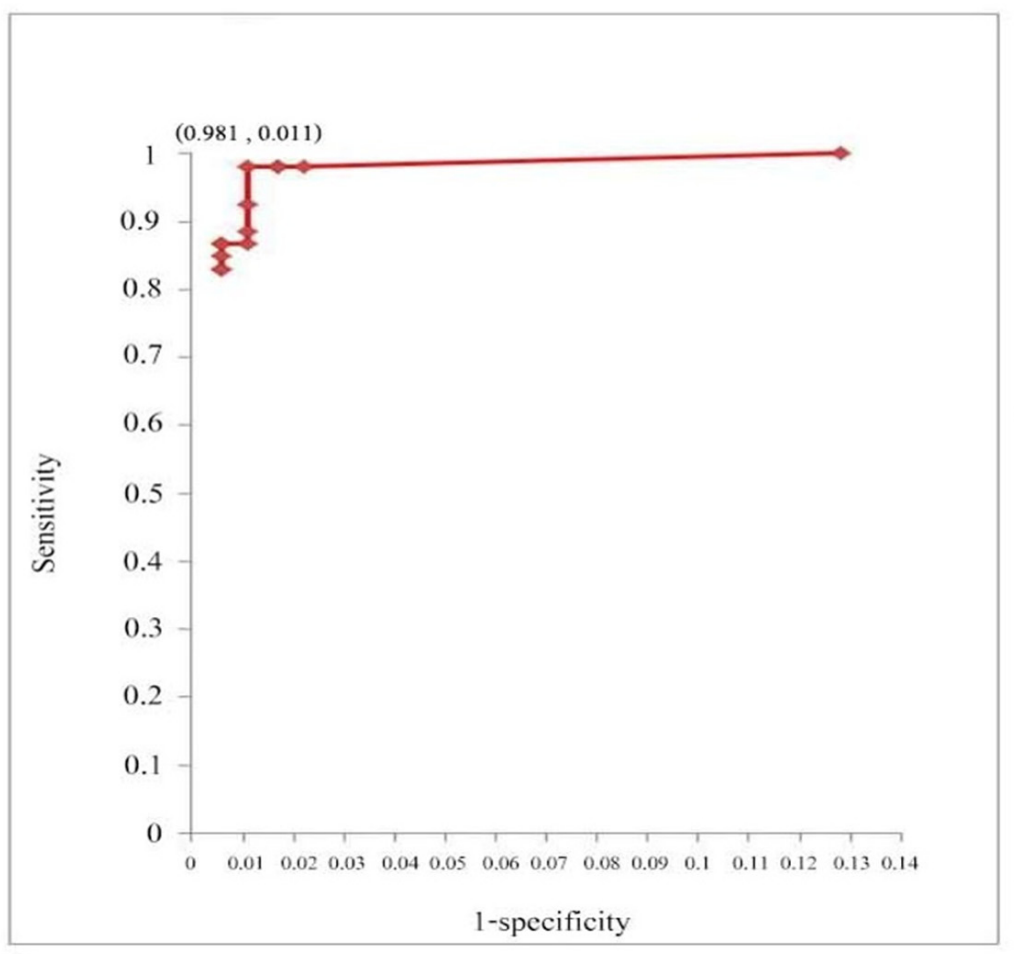

\begin{tabular}{|c|c|c|c|c|}
\hline \multicolumn{2}{|c|}{ Cut off OD } & sensitivity & specificity & 1-specificity \\
\hline mean + SD & 0.12 & 1 & 0.872 & 0.128 \\
\hline mean+ 2SD & 0.14 & 0.981 & 0.978 & 0.022 \\
\hline mean+3SD & 0.16 & 0.981 & 0.983 & 0.017 \\
\hline mean+4SD & 0.18 & 0.981 & 0.983 & 0.017 \\
\hline mean+5SD & 0.2 & 0.981 & 0.989 & 0.011 \\
\hline mean+6SD & 0.22 & 0.925 & 0.989 & 0.011 \\
\hline mean+7SD & 0.24 & 0.886 & 0.989 & 0.011 \\
\hline mean+ 8SD & 0.26 & 0.868 & 0.989 & 0.011 \\
\hline mean+9SD & 0.28 & 0.868 & 0.994 & 0.006 \\
\hline mean+10SD & 0.3 & 0.868 & 0.994 & 0.006 \\
\hline mean+11SD & 0.32 & 0.849 & 0.994 & 0.006 \\
\hline mean+12SD & 0.34 & 0.83 & 0.994 & 0.006 \\
\hline mean+13SD & 0.36 & 0.83 & 0.994 & 0.006 \\
\hline
\end{tabular}

Figure 3. Receiver operating characteristic (ROC) curve of the relationship between the sensitivity and specificity of the BmSXP-based enzyme-linked immunosorbent assay (ELISA), and the cut-off optical density (OD) values for the antifilarial immunoglobulin (Ig) G4 antibody.

\section{Discussion}

As the Global Program to Eliminate Lymphatic Filariasis (GPELF) moves towards the achievement of this goal, the prevalence of lymphatic filariasis and rates of disease transmission have decreased substantially $[9,10]$. Paradoxically with continued decline these disease levels, there is an increasing need to more sensitive and specific diagnostic assays capable of detecting low levels of parasites [11-13]. This is a major reason suggesting the use of more than one assay for surveillance monitoring in endemic areas, especially using a test with greater sensitivity, such as the antifilarial IgG4 antibody test. This assay may be a more sensitive marker of filarial infection, detecting infection earlier than those detecting antigenemia or microfilaremia [14]. Antifilarial antibody assays have been reported as potential monitoring tools. It had been reported that antibody responses to $W$. bancrofti develop prior to antigenemia, making them early markers of exposure and infection [15-17]. It appears that the antifilarial IgG4 antibody test is more sensitive than the MF thick blood film test [18]. The post-GPLF surveillance may benefit by earlier detection of re-emergence of the disease as well as helps to define pockets of ongoing filarial transmission and estimate the transmission intensity in appropriate subsections of the population, such as children of a defined age group $[19,20]$. One limitation of antifilarial antibody assay using crude $B$. malayi antigen is cross reactivity with other nematode parasites, including Stronglyloides stercoralis [21]. The usage of recombinant BmSxp protein as antigen for our developed 
ELISA in the present study can conquer this limitation and lead to the high efficacy of the assay.

In the present study, an addition to testing for antifilarial IgG4, we applied our recent published miniPCR-DLFD format to investigate $W$. bancrofti DNA. With regard to molecular based diagnosis for LF, PCR-based assays are more accurate than other tools because they detect active infections. Moreover, PCR detects infection with nocturnally periodic strains of filariae in day time blood $[11,13,17]$ and species identification by PCR is highly reliable $[2,12,22]$. The benefit of detecting parasite DNA using miniPCR-DLFD is that yields a rapid and simple visual diagnosis of LF. The miniPCR-DLFD demonstrated a high sensitivity and specificity. The assay exhibited a detection limit of 2 and $4 \mathrm{mf}$ per milliliter $(\mathrm{mL})$ of blood for B. malayi as well as W. bancrofti, respectively, and no cross-amplification was observed with other parasites [23]. The duplex lateral flow dipstick (DLFD) format can detect specific reaction mix in as little as $15 \mathrm{~min}$ and use only $2 \mu \mathrm{L}$ reaction mix, whereas agarose gel electrophoresis requires gel-analysis steps and imaging and use $10 \mu \mathrm{L}$ sample. Importantly, the developed lateral flow strip for detection of W. bancrofti amplicon showed results comparable to a conventional PCR followed by agarose gel electrophoresis.

Despite LF being the cause of high disease burden in many countries and specific endemic areas, about $65 \%$ of the infected population live in Asia, and another $30 \%$ live in Africa [24]. Moreover, there is limited reliable information about the current epidemiology of the disease, including in mainland Southeast Asia [8]. The prevalence of microfilaremia, antigenemia, and antifilarial IgG4 are useful parameters for assessing LF transmission, and to guide LF eradication program-related decision-making [5]. Collyer et al. suggested that single prevalence measurements have poor predictive power for predicting resurgence, because at low prevalence levels, random events dominate the transmission dynamics [25]. In countries that have completed multiple rounds of MDA, dramatic reductions in microfilaremia and antigenemia levels have been observed [8], thus, detection of lymphatic filaria DNA using PCR may be a useful alternative parameter due to its ability to detect low levels of parasites [13].

Our results showed the low prevalence of antifilarial IgG4 and W. bancrofti DNA ( $2 \%$ and $1.6 \%$. Mae Sot, the study area, is the main gateway between Thailand and Myanmar. Mae Sot is also an important trade hub that has a substantial population of Myanmar immigrants and refugees. The Moei River serves as a natural border between Mae Sot and Myawaddy, which is located in Myanmar's Kayin State [26]. Border bancroftian filariasis caused by $W$. bancrofti mainly exists in Myanmar immigrant communities living along the Thailand-Myanmar border. Bancroftian filariasis is endemic in 45 of the 65 districts of Myanmar, and $85.5 \%$ of the population was reported to be at risk [25]; however, published studies in the prevalence bancroftian filariasis in Myanmar are scarce [27]. One publication reported a microfilaremia prevalence ranging from $0-2 \%$ in the Mandalay, Kayin, and Yangon regions [27].

Measuring antibodies returns a cumulative/longitudinal history of the infection $[4,15]$. Thus, for all intents and purposes, the antifilarial antibody approach is much more sensitive than the parasite DNA detection by PCR which is a time point estimation. This may explain why the level of concurrence between the two methods in their 300 samples was not $100 \%$.

Studies on the prevalence of LF among Myanmar immigrants living in Thailand have been reported. Triteeraprapab and Songtrus reported a microfilaremia prevalence of $4.4 \%$ (28.8 /654) among Myanmar immigrants working in Mae Sot [28]. In 2001, Nuchprayoon et al. detected the $W$. bancrofti antigen and $S s p I$, which is a highly repeated DNA sequence of $W$. bancrofti, among Thai-Karen population in Tak Province, Thailand. The prevalence of microfilaremia, circulating antigen, and $W$. bancrofti DNA was $10 \%, 23 \%$, and $12 \%$, respectively, among the study population [29]. Chaisiri and Phantana reported a prevalence of W. bancrofti DNA rate of $18.5 \%(33 / 179)$ in human blood samples collected from bancroftian filariasis endemic areas in Tak Province [30]. From a survey performed on 433 Thai-Karen living in the Umphang District of Tak Province, the prevalence of microfilaremia, W. bancrofti antigenemia, and anti-filarial IgG4 antibody was reported to be $6 \%, 22 \%$, and $54 \%$, 
respectively [30]. Satimai et al. reported a 3.7\% prevalence of antifilarial IgG4 from their study conducted in 950 Myanmar immigrants living in Thailand [20].

Myanmar launched a National Program to Eliminate Lymphatic Filariasis (NPELF) in the year 2001 and in 2017, all implementing units covered at least 5 rounds of successful MDA. Given the current scarcity of LF prevalence data among Myanmar immigrants living in Thailand, although our study was a community-level study, the observed trends in infection prevalence are consistent with those reported from a Myanmar country-level prevalence study [31]. Moreover, our results reveal a lower prevalence for the evaluated parameters compared to previously reported prevalence rates. Therefore, our results may reflect the success of Myanmar's national program to eliminate lymphatic filariasis (NPLF) [32], as well as the success of the screening and treatment of Myanmar immigrants in Thailand conducted by the Thailand Ministry of Public Health [5].

The results of this study revealed important epidemiological data about LF on the Thai-Myanmar border. The prevalence of antifilarial IgG4 and W. bancrofti DNA was found to be $2 \%$ and $1.6 \%$, respectively. All of these prevalence rates are lower than previous reports. Nevertheless, to evaluate the success of GPELF, measure the parasite infection in the vector mosquito in the endemic areas is needed as well. Application of the developed miniPCR-DLFD assay for detecting genomic DNA from any stage of the parasite present in the mosquito will enable a faster throughput of samples, thereby increasing the efficiency of the assay.

\section{Materials and Methods}

\subsection{Study Population}

In April 2018, a total of 300 Myanmar immigrants were randomly selected from Myanmar communities living in Mae Sot, Tak province, Thailand, which is located on the Thai-Myanmar border. Peripheral venous whole blood samples that were collected (collected in daylight hours) in ethylenediaminetetraacetic acid (EDTA) tubes were used in this study (Figure 1).

\subsection{Antifilarial IgG4 Antibody Detection by ELISA Test}

\subsubsection{Cut-Off Determination}

An indirect ELISA test was developed to detect antifilarial IgG4 antibodies in plasma samples of the study population. The recombinant BmSXP protein have been produced using champion $\mathrm{pET}$ directional TOPO (pET100/D-TOPO) expression system (Thermofischer Scientific, Waltham, MA, USA) and was used as antigen for the developed ELISA. To determine the cut off of the developed assay, ELISA was performed in 100 plasma samples obtained from parasite-free, healthy subjects living in non-LF endemic areas.

The assay was performed as follows: each well of the microplate was coated individually with $100 \mu \mathrm{L}$ of the BmSXP antigen diluted in carbonate-bicarbonate buffer, $\mathrm{pH} 9.6$ $(5 \mu \mathrm{g} / \mathrm{mL})$. The ELISA plate was incubated at $4{ }^{\circ} \mathrm{C}$ overnight. The unbound antigen was washed away using phosphate-buffered saline (PBS) pH 7.4 containing $0.05 \%$ Tween-20 (PBS-T). Uncoated sites were blocked with PBS/1\% bovine serum albumin (BSA) $/ 0.2 \%$ gelatin for $1 \mathrm{~h}$ at $37^{\circ} \mathrm{C}$. After washing as described above, $100 \mu \mathrm{L}$ of plasma sample (dilution 1:100) was added into the antigen coated wells. Blank wells with only PBS, as well as positive and negative controls, were included in each plate. The plates were incubated at $37^{\circ} \mathrm{C}$ for $1 \mathrm{~h}$, washed, and then $100 \mu \mathrm{L}$ of mouse monoclonal antibody to human IgG4horseradish peroxidase (HRP) was added into each well and incubated for another $1 \mathrm{~h}$ at $37^{\circ} \mathrm{C}$. After washing, $100 \mu \mathrm{L}$ of 2,2-azino-bis (3-ethylbenzothiazoline-6-sulphonic acid) (ABTS) substrate solution was added into each well, after which the plate was kept in the dark at RT for $30 \mathrm{~min}$. The optical density (OD) of each test sample was measured at $405 \mathrm{~nm}$ using an ELISA reader (TECAN, Männedorf, Switzerland). The mean OD and standard deviation (SD) were calculated. 


\subsubsection{Sensitivity and Specificity of the Developed ELISA Test}

To determine the sensitivity of the developed ELISA test, 24 confirmed cases of bancroftian and brugian filariasis were used as true positive samples, and 100 plasma samples from parasite-free healthy subjects living in a non-endemic area were used as true negative samples. Other parasitic infections included 3 Ascaris lumbricoides, 33 Strongyloides stercoralis, 2 hookworm, 2 Capillaria phillipphinensis, 4 Ophistorchis viverrini, 3 Angiostrongylus cantonensis, and 4 Gnathostoma spinigerum. The plasma from both healthy subjects and other parasite-infected subjects was used to determine the specificity of the ELISA test.

\subsubsection{Antifilarial IgG4 Detection in the Study Population}

An indirect ELISA test using the recombinant protein BmSXP antigen was performed to detect antifilarial IgG4 antibodies in the plasma of 300 study subjects.

\subsection{Detection of W. bancrofti DNA Using a miniPCR-DLFD}

\subsubsection{DNA Extraction from Study Blood Samples}

DNA was extracted from $50 \mu \mathrm{L}$ of EDTA blood using a High Pure PCR Template Preparation Kit (Roche Diagnostics, Penzberg, Germany) according to the manufacturer's protocol. Following extraction, the DNA was eluted in $100 \mu \mathrm{L}$ of elution buffer and stored at $-20{ }^{\circ} \mathrm{C}$ until use. The DNA concentration was determined using a Nanodrop 1000 Spectrophotometer (Thermo Fisher Scientific, Waltham, MA, USA). The DNA was then subjected to polymerase chain reaction (PCR) analysis.

\subsubsection{Amplification of $W$. bancrofti DNA by Conventional PCR and by miniPCR}

DNA extracted from the 300 blood samples were amplified by conventional PCR and the miniPCR using previously published primers targeting $S s p I$ repetitive non-coding DNA sequences of $W$. bancrofti [23]. The Sequences were obtained from the National Center for Biotechnology Information database (www.ncbi.nlm.nih.gov accessed on 7 January 2022; accession number L20344.1; position 13-195) [23]. The sequences of the forward and reverse primers recognize a 182-bp region of the $S s p$ I repetitive non-coding DNA sequence of $W$. bancrofti (forward 5'-CAAAGTAGCGTAAGGGAATTG and reverse 5'CCCTCACTTACCATAAGACAAC). Conventional PCR and miniPCR were performed using the optimal PCR condition published recently [23]. Both conventional PCR and miniPCR assay used the same primer set except for miniPCR, the $5^{\prime}$ ends of the forward primers of $S s p$ I were labeled with fluorescein isothiocyanate (FITC). The $5^{\prime}$ ends of reverse primers of $S s p$ I were labeled with biotin.

For both conventional PCR and miniPCR, the amplifications were performed in a $20 \mu \mathrm{L}$ volume consisting of $10 \mu \mathrm{L}$ of PCR Master Mix [23] (QuantaBio, Beverly, MA, USA), $0.2 \mu \mathrm{M}$ of the forward and reverse primers, $7.2 \mu \mathrm{L}$ of $\mathrm{dH}_{2} \mathrm{O}$, and $2 \mu \mathrm{L}$ DNA template. Nuclease-free water was used as a negative control. DNA from blood samples containing $\mathrm{mf}$ of $W$. bancrofti were used as positive controls. The amplification condition included an activation step at $95^{\circ} \mathrm{C}$ for $5 \mathrm{~min}$, followed by a 30-step amplification for $30 \mathrm{~s}$ at $95{ }^{\circ} \mathrm{C}, 30 \mathrm{~s}$ at $56^{\circ} \mathrm{C}$, and $30 \mathrm{~s}$ at $70{ }^{\circ} \mathrm{C}$, with a final step at $70{ }^{\circ} \mathrm{C}$ for $5 \mathrm{~min}$.

\subsubsection{Detection of the Amplicon Using Agarose Gel Electrophoresis}

Ten microliters of reaction mix obtained from conventional PCR amplification was separated by $1.5 \%$ agarose gel-electrophoresis, stained with GelRed Prestain Dye (Biotium, Fremont, CA, USA), and visualized under ultraviolet (UV) illumination.

\subsubsection{Detection of the Amplicon Using the Duplex Lateral Flow Dipstick (DLFD)}

Two microliters of reaction mix obtained from a miniPCR amplification from each sample were added into a well of a 96-well plate containing $100 \mu \mathrm{L}$ of sample buffer. The duplex lateral flow dipstick was placed into the well vertically, and the reaction was read within $15 \mathrm{~min}$. A positive result was indicated by the appearance pink-colored lines 
observable by naked eye on both the test and control lines. For a negative result, the pink-colored line was apparent only on the control line [23].

\subsection{Data Analysis}

SPSS Statistics version 13 (SPSS, Inc., Chicago, IL, USA) was used non-parametric descriptive measures. Depending on the type and distribution of data, the results were reported as number and percentage, mean plus/minus standard deviation, or median and range. A percentage measure of dispersion was also calculated. A receiver operating characteristic (ROC) curve was used to determine the cut-off OD with the most favorable overall sensitivity and specificity for detecting antifilarial IgG4 [33,34]. ROC curve analysis was performed to identify the cut-off optical density (OD) value with the greatest sensitivity and specificity for detecting antifilarial IgG4 using the ELISA test developed in this study.

Author Contributions: S.W. contributed for conceptualization, methodology, manuscript editing, and project administration. D.P. contributed for conceptualization, project administration, and funding acquisition. P.W. and L.K. contributed for recombinant antigen production. A.P. contributed for investigation. N.K. contributed for investigation and writing first draft of the manuscript. All authors have read and agreed to the published version of the manuscript.

Funding: This research was funded by Thammasat University Research Fund (fund No. TUGG 147/2562) and The King Prajadhipok and Queen Rambhaibarni memorial foundation fund (fund No. FUND 2562).

Institutional Review Board Statement: This study was conducted in accordance with the principles and guidelines set forth in the Declaration of Helsinki, and the protocol for this study was approved by the Ethical Committee of the Faculty of Medicine Siriraj Hospital, Mahidol University, Bangkok, Thailand (certificate of approval no. Si297/2017 and Si091/2021).

Informed Consent Statement: Informed consent was verbally obtained from all subjects involved in this study before data and sample collection.

Data Availability Statement: Data is contained within the article.

Acknowledgments: The authors gratefully acknowledge the Myanmar immigrants that generously agreed to participate in this study; Bungon Sermsart and Jeerawan Onrochjanakhul of the Department of Parasitology, Faculty of Medicine Siriraj Hospital, Mahidol University for laboratory assistance; and, the staff of the Pikhunthong Royal Project, Narathiwat Province, Thailand for their assistance with field blood collection.

Conflicts of Interest: The authors declare no conflict of interest.

\section{Abbreviations}

$\mathrm{ROC}=$ receiver operating characteristic; $\mathrm{DLFD}=$ duplex lateral flow dipstick; $\mathrm{OD}=\mathrm{op}-$ tical density; $\mathrm{ABTS}=$ 2,2-azino-bis (3-ethylbenzothiazoline-6-sulphonic acid); $\mathrm{LF}=$ lymphatic filariasis.

\section{References}

1. Taylor, M.J.; Hoerauf, A.; Bockarie, M. Lymphatic filariasis and onchocerciasis. Lancet 2010, 376, 1175-1185. [CrossRef]

2. Ottesen, E.A.; Duke, B.O.L.; Karam, M.; Behbehani, K. Strategies and tools for the control/elimination of lymphatic filariasis. Bull. World Health Org. 1997, 75, 491-503. [PubMed]

3. WHO. Lymphatic filariasis: The disease and its control. In Fifth Report of the WHO Expert Committee on Filar Nnnias is World Health Organization Technical Report Series; WHO: Geneva, Switzerland, 1992; pp. 1-71.

4. Wongkamchai, S.; Boitano, J. A move toward defeating lymphatic filariasis. Siriraj Med. J. 2010, 62, 93-97.

5. Rojanapanus, S.; Toothong, T.; Boondej, P.; Thammapalo, B.; Khuanyoung, N.; Santabutr, W.; Prempree, P.; Gopinath, D.; Ramaiah, K.D. How Thailand eliminated lymphatic filariasis as a public health problem. Infect. Dis. Poverty 2019, 8, 38. [CrossRef] [PubMed] 
6. Win, K.M.; Tripathy, J.P.; Maung, T.M.; Oo, T.; Aung Thi, K.N.; Lon, K.N.; Lin, Z. Rapid progress towards elimination of lymphatic filariasis in endemic regions of Myanmar as a result of 16 years of antifilarial activities (2001-2016). Trop. Med. Health 2018, 46, 14. [CrossRef]

7. Duerr, H.P.; Dietz, K.; Eichner, M. Determinants of the eradicability of filarial infections: A conceptual approach. Trends Parasitol. 2005, 21, 88-96. [CrossRef]

8. Gass, K.; Rochars, M.; Boakye, D.; Bradley, M.; Fischer, P.U.; Gyapong, J.; Itoh, M.; Ituaso-Conway, N.; Joseph, H.; Kyelem, D.; et al A multicenter evaluation of diagnostic tools to define endpoints for programs to eliminate bancroftian filariasis. PLoS Negl. Trop. Dis. 2012, 6, e1479. [CrossRef]

9. Ichimori, K.; King, J.D.; Engels, D.; Yajima, A.; Mikhailov, A.; Lammie, P.; Ottesen, E.A. Global Programme to Eliminate Lymphatic Filariasis: The Processes Underlying Programme Success. PLoS Negl. Trop. Dis. 2014, 8, e3328. [CrossRef]

10. Ramaiah, K.D.; Ottesen, E.A. Progress and Impact of 13 Years of the Global Programme to Eliminate Lymphatic Filariasis on Reducing the Burden of Filarial Disease. PLoS Neglected. Trop. Dis. 2014, 8, e3319. [CrossRef]

11. Pilotte, N.; Torres, M.; Tomaino, F.; Laney, S.; Williams, S. A TaqMan-based multiplex real-time PCR assay for the simultaneous detection of Wuchereria bancrofti and Brugia malayi. Mol. Biochem. Parasitol. 2013, 189, 33-37. [CrossRef]

12. Fischer, P.; Supali, T.; Wibowo, H.; Bonow, I.; Williams, S. Detection of DNA of nocturnally periodic Brugia malayi in night and day blood samples by a polymerase chain reaction-ELISA-based method using an internal control DNA. Am. J. Trop. Med. Hyg. 2000, 62, 291. [CrossRef] [PubMed]

13. Plichart, C.; Lemoine, A. Monitoring and evaluation of lymphatic filariasis interventions: An improved PCR-based pool screening method for high throughput Wuchereria bancrofti detection using dried blood spots. BioMed Central. 2013, 6, 110. [CrossRef] [PubMed]

14. Lammie, P.J. Research directly linked with GPELF activities (operational research). 2.1 Essential tools-diagnostics. Am. J. Trop. Med. Hyg. 2004, 71 (Suppl. S5), 3-6. [CrossRef]

15. Lammie, P.J.; Reiss, M.D.; Dimock, K.A.; Streit, T.G.; Roberts, J.M.; Eberhard, M.L. Longitudinal analysis of the development of filarial infection and antifilarial immunity in a cohort of Haitian children. Am. J. Trop. Med. Hyg. 1998, 59, 217-221. [CrossRef] [PubMed]

16. Weil, G.J.; Ramzy, R.M.R.; El Setouhy, M.; Kandil, A.M.; Ahmed, E.S.; Faris, R. A longitudinal study of bancroftian filariasis in the Nile Delta of Egypt: Baseline Data and one-year follow-up. Am. J. Trop. Med. Hyg. 1999, 61, 53-58. [CrossRef] [PubMed]

17. Wongkamchai, S.; Rochjanawatsiriroj, C.; Monkong, N.; Nochot, H.; Loymek, S.; Jiraamornnimit, C.; Hunnangkul, S.; Choochote, W. Diagnostic value of IgG isotype responses against Brugia malayi antifilarial antibodies in the clinical spectrum of brugian filariasis. J. Helminthol. 2006, 80, 363-367. [CrossRef] [PubMed]

18. Jiraamonnimit, C.; Wongkamchai, S.; Boitano, J.; Nochot, H.; Loymek, S.; Chujun, S.; Yodmek, S. A cohort study on anti-filarial IgG4 and its assessment in good and uncertain MDA-compliant subjects in brugian filariasis endemic areas in southern Thailand. J. Helminthol. 2009, 83, 351-360. [CrossRef]

19. Chanteau, S.; Glaziou, P.; Plichart, C.; Luquiaud, P.; Moulia-Pelat, J.P.; N'Guyen, L.; Cartel, J.L. Wuchereria bancrofti filariasis in French Polynesia: Agespecific patterns of microfilaraemia, circulating antigen, and specific IgG and IgG4 responses according to transmission level. Int. J. Parasitol. 1995, 25, 81-85. [CrossRef]

20. Satimai, W.; Jiraamonnimit, C.; Thammapalo, S.; Choochote, W.; Luenee, P.; Boitano, J.J.; Wongkamchai, S. The impact of a national program to eliminate lymphatic filariasis in selected Myanmar immigrant communities in Bangkok and Ranong Province, Thailand. Southeast Asian J. Trop. Med. Public. Health 2011, 42, 1054-1064.

21. Muck, A.E.; Pires, M.L.; Lammie, P.J. Influence of infection with non-filarial helminths on the specificity of serological assays for antifilarial immunoglobulin G4. Trans. R. Soc. Trop. Med. Hyg. 2003, 97, 88-90. [CrossRef]

22. Lizotte, M.R.; Supali, T.; Partono, F.; Williams, S.A. A Polymerase Chain Reaction Assay for the Detection of Brugia Malayi in Blood. Am. J. Trop. Med. Hyg. 1994, 51, 314-321. [CrossRef] [PubMed]

23. Phuakrod, A.; Sripumkhai, W.; Jeamsaksiri, W.; Pattamang, P.; Loymek, S.; Brindley, P.J.; Sarasombath, P.T.; Wongkamchai, S. A miniPCR-duplex lateral flow dipstick platform for rapid and visual diagnosis of lymphatic filariae infection. Diagnostics 2021, 11, 1855. [CrossRef]

24. WHO. Towards Eliminating Lymphatic Filariasis: Progress in the South-East Region (2001-2011); World Health Organization Regional Office for South-East Asia: New Delhi, India, 2013.

25. Collyer, B.S.; Irvine, M.A.; Hollingsworth, T.D.; Bradley, M.; Anderson, R.M. Defining a prevalence level to describe the elimination of Lymphatic Filariasis (LF) transmission and designing monitoring \& evaluating (M\&E) programmes post the cessation of mass drug administration (MDA). PLoS Negl. Trop. Dis. 2020, 14, e0008644. [CrossRef]

26. Wikipedia. Available online: https://en.wikipedia.org/wiki/Mae_Sot_District (accessed on 10 August 2021).

27. Dickson, B.F.R.; Graves, P.M.; McBride, W.J. Lymphatic Filariasis in Mainland Southeast Asia: A Systematic Review and Meta-Analysis of Prevalence and Disease Burden. Trop. Med. Infect. Dis. 2017, 2, 32. [CrossRef] [PubMed]

28. Triteeraprapab, S.; Songtrus, J. High prevalence of Wuchereria bancrofti infection among Myanmar migrants in Thailand. Ann. Trop. Med. Parasitol. 2001, 95, 535-538. [CrossRef] [PubMed]

29. Nuchprayoon, S.; Yentakam, S.; Sangprakarn, S.; Junpee, A. Endemic bancroftian filariasis in Thailand: Detection by Og4C3 antigen capture ELISA and the polymerase chain reaction. J. Med. Assoc. Thai. 2001, 84, 1300-1307. 
30. Chansiri, K.; Phantana, S. A polymerase chain reaction assay for the survey of bancroftian filariasis. Southeast Asian J. Trop. Med. Public Health 2002, 33, 504-508.

31. Nuchprayoon, S.; Sanprasert, V.; Porksakorn, C.; Nuchprayoon, I. Prevalence of bancroftian filariasis on the Thai-Myanmar border. Asian Pac. J. Allergy Immunol. 2003, 21, 179-188.

32. Aye, Z.; Lin, N.N.; Lon, K.N.; Linn, N.Y.Y.; Nwe, T.W.; Mon, K.M.; Ramaiah, K.; Betts, H.A. Kelly-Hope (2018) Mapping and modelling the impact of mass drug adminstration on filariasis prevalence in Myanmar. Inf. Dis. Poverty 2018, 7, 56. [CrossRef]

33. Akobeng, A.K. Understanding diagnostic tests 1: Sensitivity, specificity and predictive values. Acta Paediatr. 2007, 96, 338-341. [CrossRef]

34. Akobeng, A.K. Understanding diagnostic tests 3: Receiver operating characteristic curves. Acta Paediatr. 2007, 96, 644-647. [CrossRef] [PubMed] 